\title{
COMPARISON OF APICAL TRANSPORTATION, CENTERING ABILITY AND CYCLIC FATIGUE RESISTANCE OF FOUR ROTARY FILE SYSTEMS
}

\author{
Ankita Sood, ${ }^{1}$ Varun Jindal, ${ }^{2}$ Ajay Chhabra, ${ }^{3}$ Arvind Arora, ${ }^{4}$ Ankur Vats ${ }^{5}$ \\ ${ }^{1}$ PG Student, Department of Conservative Dentistry \& Endodontics, Bhojia Dental College and Hospital, Himachal Pradesh, India \\ ${ }^{2}$ Reader, Department of Conservative Dentistry \& Endodontics, Bhojia Dental College and Hospital, Himachal Pradesh, India \\ ${ }^{3}$ Professor \& Head, Department of Conservative Dentistry \& Endodontics, Bhojia Dental College and Hospital, Himachal Pradesh, India \\ ${ }^{4}$ Professor, Department of Conservative Dentistry \& Endodontics, Bhojia Dental College and Hospital, Himachal Pradesh, India \\ ${ }^{5}$ Sr. Lecturer, Department of Conservative Dentistry \& Endodontics, Bhojia Dental College and Hospital, Himachal Pradesh, India
}

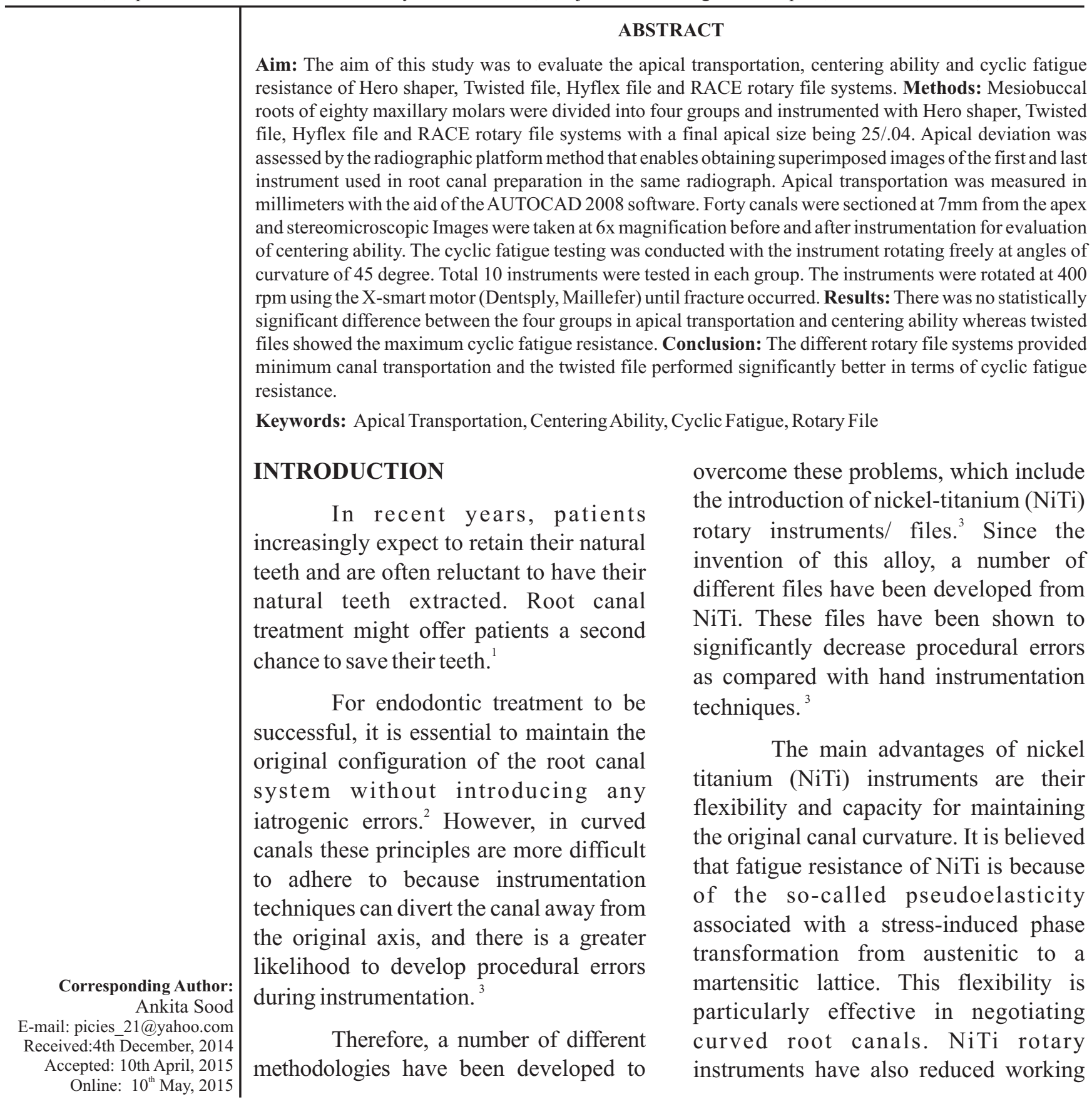


time, operator fatigue and procedural errors associated with root canal instrumentation. ${ }^{4}$

In order to keep pace with the progress of advanced root canal preparation techniques, new endodontic rotary instruments have been developed with a special focus on higher cutting efficiency and improved resistance to cyclic fatigue through innovative mechanical design and meticulous raw material selection. The new rotary files incorporate variety of tip designs such as cutting, non-cutting or partially cutting tips. The tip design helps the file to stay centered with the canal and effects shaping of the root canal system. ${ }^{5}$

Despite the many advantages of rotary Ni-Ti instruments, concern has been expressed by many authors and clinicians about the potential for rotary $\mathrm{Ni}$ Ti instrument to fracture within the root canal system during endodontic treatment. Two modes of fracture of $\mathrm{NiTi}$ endodontic instruments have been identified in clinical situation, Torsional failure and Flexural failure. ${ }^{6}$

Even though the NiTi rotary files carry a disadvantage to separate in the root canal, they are being widely used to clean and shape the root canals during the endodontic therapy. So, the main parameters which should be used to evaluate a technique or an instrument that has been developed for root canal preparation should be "shaping root canal whilst protecting the curvature of the canal" and "adequately cleaning the root canal walls". In this context new instruments are idealised, several techniques are modified and others are developed to shape and clean the root canals but it is quite difficult to determine the best one. ${ }^{6}$

Few of the available rotary sytems in market are for e.g. RaCe instruments (FKG Dentaire, LaChauxde-Fonds, Switzerland) which have a triangular cross-sectional design, except for the smaller instruments (15/0.02 and 20/0.02), which have a square cross-sectional design. According to the manufacturer, the combination of the triangular cross section with sharp edges and alternating cutting edges enhances cutting efficiency and ensures efficient debris evacuation. In addition, the surface of $\mathrm{RaCe}$ instruments are treated electrochemically to enhance the cutting efficacy, and they have a non cutting tip.

Twisted file instruments are created by a proprietary process (R-phase) in which NiTi cannot be ground but can be twisted. The TF technology was developed to increase the NiTi rotary instrument resistance to cyclic fatigue, and provide superior mechanical properties. The special surface treatment increases the flexibility, which enables the original canal curvature to be maintained and minimises the apical transportation. ${ }^{8}$

Another recent development is the fabrication of instruments with shape memory (e.g. Coltene Hyflex CM; Coltene Whaledent, Cuyahoga Falls, $\mathrm{OH}$, USA). Hyflex rotary instruments are fabricated from NiTi wire that is subjected to a proprietary process. The manufacturer claims that these instruments are up to $300 \%$ more fatigue-resistant have no rebound and regain their shape after sterilization. Hyflex files are extremely flexible but without the shape memory of conventional NiTi files. ${ }^{9}$

The Hero Shaper is a new system that supplements the existing Hero 642. The Hero Shaper helix angle increases from the tip to the shank that is claimed to reduce threading, while the pitch varies according to the taper and it is claimed to increase the efficiency, the flexibility and the strength of the instruments. It also has a non cutting tip which allows the file to follow the canal anatomy.

Due to the availability of numerous rotary systems it is imperative to analyse the performance of these systems that are released in the market to prove the accuracy with regard to morphologic alterations that may occur in the root canal submitted to endodontic treatment. Thus, the aim of this study was to assess the apical transportation, cyclic fatigue and centering ability of RACE, Hero Shapers, Twisted files and Hyflex rotary file sytems.

\section{MATERIAL AND METHODS}

Eighty human maxillary molars with complete root formation were selected for the study. Any residual caries or old restoration was removed from the teeth crowns and then an access cavity was prepared using a number 4 round bur and high speed handpiece with water spray. The occlusal surface was flattened to have 
a comparable length for all teeth and hence a reliable reference point for instrumentation. The working length was established for the mesiobuccal canal using a no. $15 \mathrm{k}$-file till the point at which it was visible at the apical foramen. The distance between the file tip and the rubber stopper was measured and subsequently, $0.5 \mathrm{~mm}$ was subtracted from this measurement and the resulting value was taken as the working length.

The teeth were then divided into four groups of 20 each as follows:

Group 1: was assigned to preparation with RACE system.

Group 2: was assigned to preparation with Hero Shaper system.

Group 3: was assigned to preparation with Twisted file system.

Group 4: was assigned to preparation with Hyflex file system.

Each group was further sub-divided into two sub-groups A and B of ten each. The teeth in subgroup A were assigned to evaluate the centering ability and those in subgroup B were assigned to evaluate the apical transportation.

\section{Evaluation of apical transportation:}

A customised jig was designed to provide a reproducible position for the dental X-ray film and cone alignment. A No. $15 \mathrm{~K}$-file was placed in the root canal till working length and a radiograph was obtained for each tooth. All the canals were prepared in a crown down technique. The final apical preparation will be set to $25 / 0.04$. After each use, the files were cleaned and inspected for damage, and the canals were irrigated with $5.25 \%$ sodium hypochlorite. The patency was verified repeatedly with a No.15 k-file. After shaping, the memory instrument was placed in the canal at working length, the tooth was repositioned on the radiographic jig and a post instrumentation radiograph was taken. Therefore, superimposed images were obtained of the first and last instrument used; and the presence of apical deviation was analyzed after instrumentation. Periapical radiographs were digitalized with the aid of a digital camera (Sony, DSCW630) and imported into the AUTOCAD 2008 software in order to analyze the deviation of the original root canal path in the apical third. When both instruments were superimposed in a manner that their extremities could not be differentiated, apical deviation would have not occurred. On the other hand, when the alteration occurred in the original position of the root canal, superimposition would have occurred, leading to the visualization of the tip of the two distinct files. The distance between these files were measured in millimeters which showed the deviation of the original mesio-buccal canal path in the apical third.

\section{Evaluation of centering ability:}

For the evaluation of the centering ability the mesiobuccal roots of the maxillary molars was sectioned at the level of the furcation and submitted to stereomicroscopic examination. Further the sectioned root was prepared by the respective file system of the group in the similar manner described above. Then the prepared root sections were again examined under the stereomicroscope. The images were then imported to Adobe Photoshop and the following formula was applied to check whether the canal remained centered or not.

$$
\text { a1-b1/ a2-b2 }
$$

If these numbers are not equal, the lower figure is considered as the numerator of the ratio. According to this formula, a result of 1 indicates perfect centering.

\section{Evaluation of cyclic fatigue :}

A simulated working model was created. Three cylindrical steel blocks were taken, one supporting block and two shaping blocks were attached on a $6 \mathrm{~mm}$ thick wooden block. The position of shaping block was adjusted so as to get the desired angle of 45 degrees. The angle of curvature was calculated by Schneider's method which defined the angle of curvature by drawing a line parallel to the long axis of the canal and the outer line from the apical foramen to intersect with first line at a point wherein the root canal began to leave the long axis of the canal. Ten instruments were tested for each of the four experimental groups with the angle of curvature being 45 degrees. The instruments were rotated at a fixed speed of 400rpm using the rotary handpiece (Xsmart Dentsply) and the time and the number of rotations to fracture of instrument was recorded using a stop (Figure 1). 

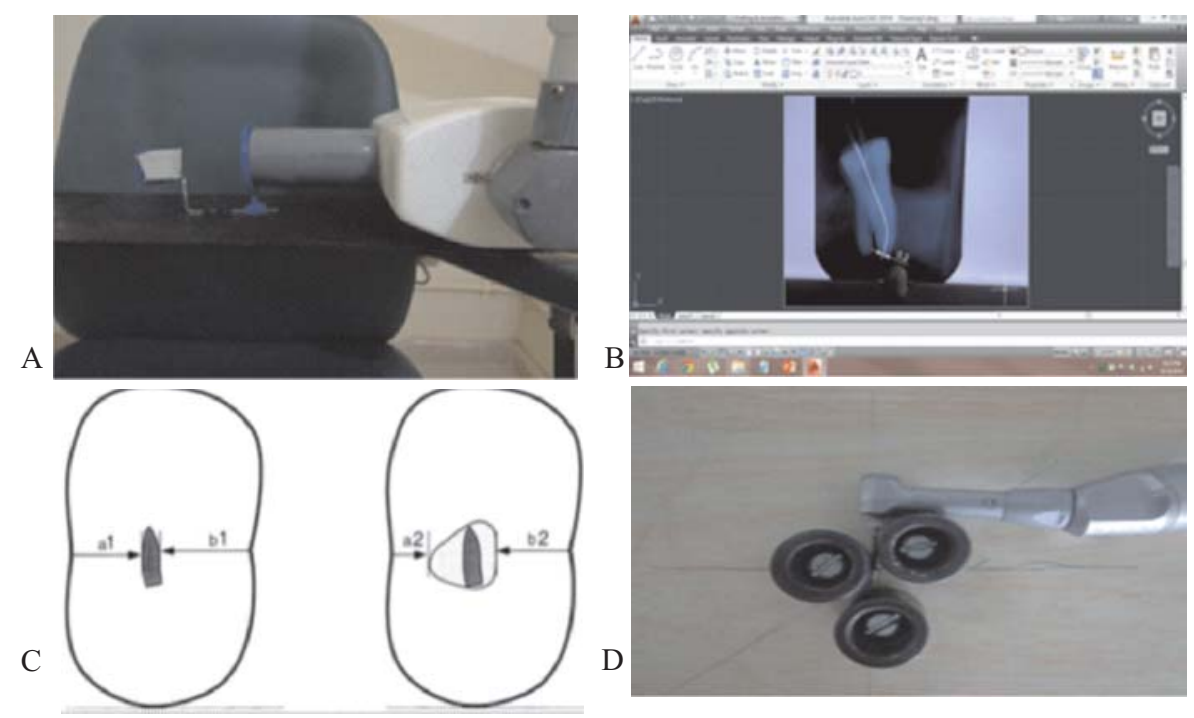

Figure 1: A: Radiographic platform, B: Measurement in autocad AUTOCAD, C: uninstrumented and instrumented images for centering ability measurements, D: cyclic fatigue testing model

\section{RESULTS:}

The Kruskal-Wallis test was used for the statistical analysis of the data.

\section{Cyclic Fatigue}

The mean NCF values were noted for RACE, Hero Shapers, Twisted and Hyflex file systems as $349.600,432.5000,783.5000$ and 672.000 respectively and standard deviation is provided in tables. A statistically significant difference was found between RACE, Hero shapers, Twisted and Hyflex NiTi instruments. $(\mathrm{P}<0.05)$.

Mathematically it can be shown that Twisted $>$ Hyflex $>$ Hero Shaper $>$ RACE.

\section{Apical transportation}

The mean values for apical transportation measured at $1.5 \mathrm{~mm}$ from the apex for RACE, Hero shapers, Twisted and Hyflex file systems were .029, $.050, .00$ and .045 respectively. Two samples were excluded from the study due to separation of file in the apical third region. Remaining 38 teeth were included in the ststistical analysis. The Kruskal-wallis test showed no statistically significant difference between the four groups. $(\mathrm{P}=.502)$

\section{Centering ability}

The mean values for centering ability measured at $7 \mathrm{~mm}$ from the apex for RACE, Hero shapers, Twisted and Hyflex file systems were 0.87, $0.92,0.79, .095$ respectively. The Kruskal-wallis test showed no statistically significant difference between the four groups $(\mathrm{P}=.538)$ (Table 1-6).

Table 1: Comparison of all four groups

\begin{tabular}{|l|c|c|c|c|c|}
\hline & Race & Hero & Twisted & Hyflex & p-value \\
\hline 1st Parameter & 5.5 & 15.5 & 35.5 & 25.5 & $<.001^{* *}$ \\
\hline 2nd Parameter & 20.1 & 22.1 & 18 & 21.8 & .502 \\
\hline 3rd Parameter & 20.1 & 21.8 & 17.9 & 22.2 & .583 \\
\hline
\end{tabular}

Table 2: Comparison of group 1 with group 2

\begin{tabular}{|l|c|c|c|}
\hline & Race & Hero & p-value \\
\hline 1st Parameter & 5.5 & 15.5 & $<.001^{* *}$ \\
\hline 2nd Parameter & 10.00 & 11.00 & .543 \\
\hline 3rd Parameter & 10.05 & 10.95 & .584 \\
\hline
\end{tabular}

Table 3: Comparison of group 1 with group 3

\begin{tabular}{|l|c|c|c|}
\hline & Race & Twisted & p-value \\
\hline 1st Parameter & 5.50 & 15.50 & $<.001^{* *}$ \\
\hline 2nd Parameter & 11.00 & 10.00 & .317 \\
\hline 3rd Parameter & 11.05 & 9.95 & .585 \\
\hline
\end{tabular}

Table 4: Comparison of group 1 with group 4

\begin{tabular}{|l|c|c|c|}
\hline & Race & Hyflex & p-value \\
\hline 1st Parameter & 5.50 & 15.50 & $<.001^{* *}$ \\
\hline 2nd Parameter & 10.10 & 10.90 & .627 \\
\hline 3rd Parameter & 9.95 & 11.05 & .503 \\
\hline
\end{tabular}

Table 5: Comparison of group 2 with group 3

\begin{tabular}{|l|c|c|c|}
\hline & Hero & Twisted & p-value \\
\hline 1st Parameter & 5.50 & 15.50 & $<.001^{* *}$ \\
\hline 2nd Parameter & 11.50 & 9.50 & .147 \\
\hline 3rd Parameter & 11.45 & 9.55 & .304 \\
\hline
\end{tabular}

Table 6: Comparison of group 2 with group 4

\begin{tabular}{|l|c|c|c|}
\hline & Hero & Hyflex & p-value \\
\hline 1st Parameter & 5.50 & 15.50 & $<.001^{* *}$ \\
\hline 2nd Parameter & 10.55 & 10.45 & .957 \\
\hline 3rd Parameter & 10.45 & 10.55 & .942 \\
\hline
\end{tabular}




\section{DISCUSSION}

Literature focusing on the mechanical and chemical preparation of root canals consistently points to the importance of disinfection. ${ }^{10,11}$ The need for canal enlargement, and at the same time the need to preserve root canal anatomy, represents a paradigm for clinicians and specialists. Apical transportation may result in "zipping" of the canal, which could give rise either to an hourglass-shaped canal at the apical terminus or to a ledge or perforation. ${ }^{12}$ On the one hand, the wear commonly associated with the use of endodontic instruments should be controlled; on the other hand, contaminated dentin needs to be removed. ${ }^{11}$

The clinical use of nickel-titanium rotary instruments is growing; however, these instruments suffer from the limitation of having relatively short working lives. The use of these instruments in severely curved canals is particularly taxing because the prevailing conditions predispose them to low-cycle, high-amplitude fatigue. ${ }^{13}$ Most clinical guidelines and manufacturers' recommendations for instrumentation with rotary NiTi instruments call for the reduction of the canal curvature by creating straight-line access and the reduction of interference in the middle and coronal third by classic or modified crown-down techniques.39 However, clinically, a perfect straight-line access may not always be possible, so a rotary NiTi instrument may as well engage in a lateral cutting action while working in a curved canal. This is frequently observed during the instrumentation of molars with difficult or limited access. ${ }^{14}$

Cyclic fatigue resistance refers to the number of cycles to fracture (NCF) that an instrument is able to resist under a specific loading condition. Because the NCF is cumulative, it is calculated by multiplying the rotational speed by the time elapsed until fracture. ${ }^{15}$ No standardized testing devices are currently in existence. Although the extracted tooth model more closely resembles the clinical situation, it is not an ideal model to compare the pure physical properties of NiTi files because no 2 root canals are perfectly identical, ${ }^{16}$ and it is impossible to control the intensity of stress in the rotating-bending area of the instrument because of differences in the canal curvature. ${ }^{17}$ Thus, a non-tooth model was selected to standardize the conditions.
Various cyclic fatigue studies have used $30,45,60$, and 90 degree angles of curvatures. One author reported that 30 degree angle of curvature did not sufficiently constrain the instruments in the canal. ${ }^{18}$ Thus, a 45 degree angle of curvature of the canal was chosen for the present study.

The rotational speed at which NiTi rotary instruments should be driven is a variable that remains to be clarified. The instruments were rotated at a fixed speed of 400 rotations per minute for all the systems and to reduce the friction of the file, synthetic oil was applied as recommended by Grande et al. ${ }^{19}$

In the present study, TF 25/.04 exhibited the greatest mean NCF of 783.5 representing the major role of new manufacturing process in increasing the resistance to fatigue of NiTi rotary instruments. This can be explained by the fact that the traditional grinding process results in formation of micro-cracks and defects along the surface of the instruments and within the internal structure that can cause stress concentration points that weaken the instruments and can lead to intracanal failure. ${ }^{20}$

This hypothesis is in consonance with the views of other researchers. Kim et $\mathrm{al}^{21}$ conducted a study to evaluate the fatigue resistance of TF and 3 other traditional NTR instruments and concluded that instruments with abundant machining grooves seemed to have a higher risk of fatigue. Similarly, Rodrigues et $\mathrm{al}^{22}$ while evaluating the NCF by static and dynamic fatigue tests, attributed the higher NCF values of TF in comparison to $\mathrm{RaCe}$ to the manufacturing process involving twisting coupled with heat treatment.

The comparison of canal transportation caused by the rotary systems was measured at $1.5 \mathrm{~mm}$ from the major apical foramen (apical transportation) and at the coronal level of $7 \mathrm{~mm}$ from the apex (centering ability). Apical deviation can be evaluated by several methods and the most commonly used are radiographic methods, silicone impressions of the root canals, analysis of the histological section, scanning electron microscopy and computed tomography. ${ }^{23}$ For this research, the radiographic platform method developed by Sidney et al ${ }^{24}$ was chosen. For the centering ability stereomicroscopic images were made at a level of $7 \mathrm{~mm}$ from the apex, pre and post instrumentation and then compared. 
Mesiobuccal root canals of extracted human maxillary molars were used in the present study because they usually present an accentuated curvature and mesiodistal flattening. ${ }^{25}$ These characteristics are additional shortcomings during chemomechanical instrumentation and make cleaning and shaping of these canals more difficult, mainly in the isthmus areas. ${ }^{26}$ The crowns were maintained to simulate, as closely as possible, the clinical endodontic practice, in which the interference of cervical dentin projections creates tensions on the files during root canal instrumentation.

Irrigation was carried out by sodium hypochlorite and 17\% EDTA trisodium solution, as proposed by Peters et al. ${ }^{27}$ This irrigation method prevents smear layer compaction resulting from the action of instruments in contact with the root canal walls, thus avoiding loss of working length and minimizing original root canal transportation.

When comparing the four systems under study no statistically significant difference was found. The mean values for apical transportation measured at $1.5 \mathrm{~mm}$ from the apex for RACE, Hero shapers, Twisted and Hyflex file systems were $.029, .050, .00$ and .045 respectively, demonstrating that all the four groups produced very low values of apical deviation. $(\mathrm{P}=.502)$. $\mathrm{Wu}$ et $\mathrm{al}^{28}$ observed that the apical transportation greater than $0.3 \mathrm{~mm}$ reduces the sealing quality of the root filling. We found that none of the instrumented samples reached the aforementioned critical level of apical transportation. The mean values for centering ability measured at $7 \mathrm{~mm}$ from the apex for RACE, Hero shapers, Twisted and Hyflex file systems were $0.87,0.92,0.79, .095$ respectively $(\mathrm{P}=.538)$ indicating no statistically significant difference between the four groups.

These results are in agreement with those of Fernando et $\mathrm{al}^{29}$ who compared Twisted files with Flexmaster and found no statistically significant difference between the two. The results also agree with those of Laila Gonzales et $\mathrm{al}^{30}$ who showed no significant difference between Twsisted files and Endosequence. Zhao et $\mathrm{al}^{31}$ showed no statistical difference in canal transportation between TF and Hyflex files. The fact that TF instruments provided a centered preparation while maintaining the original shape of the curved canal is because TF is provided with R-phase treatment and are manufactured by twisting NiTi wire, the surface deoxidation of these file which might explain its high flexibility, even hyflex files provided a centered preparation while maintaing the original shape of the curved canals. HyFlex ${ }^{\circledR}$ $\mathrm{CM}^{\mathrm{TM}} \mathrm{NiTi}$ files have been manufactured with a unique process that controls the material's memory, making the files extremely flexible. This increases the ability of the file to follow the anatomy of the canal very closely, and reduces the risk of ledging, transportation and perforation.

Pasternek et $\mathrm{al}^{32}$ found that the RaCe files remained centered in the canal and did not cause any significant canal transportation. Marc Gracia et $\mathrm{al}^{11}$ also found no significant difference between Profile and RaCe instruments in terms of canal transportation. This finding differs from the results obtained by Al- Sudani and Al-Shahrani who reported that the RaCe system resulted in more transportation than the ProFile system. However, the results of our study cannot be compared directly with those of Al- Sudani and Al-Shahrani because of the different area of the root canal under study. Al-Sudani and Al-Shahrani examined transportation at 3,6 , and $8 \mathrm{~mm}$ from the root apex, whereas the present study focused exclusively on transportation at $1.5 \mathrm{~mm}$ from the root apex.

The flexibility of root canal instruments depends on complex interrelationships among different parameters, such as the cross-sectional design, core diameter, pitch, metallurgical properties, and surface treatment of the instruments. ${ }^{32}$ The most common way to increase file flexibility is to decrease the metal mass of the file by increasing the number of spirals or flutes per unit length; increasing the depth of the flutes; and decreasing the taper, size, and/or core diameter of the file. ${ }^{5}$ Given that an increase in the taper reduces instrument flexibility, the size of the taper is a key factor in root apical transportation. ${ }^{33}$

The present study showed lower mean apical deviation when compared with the other studies. This is probably because the rotary techniques were used up to the file corresponding to the diameter of file no. 25 , and other studies performed instrumentation up to the file corresponding to the diameter of file no. 30 . 
Therefore, it shows that instrumentation up to the file corresponding to the diameter of file no. 25 must be used with caution.

\section{CONCLUSION}

The different rotary file systems provided minimum canal transportation and the twisted file performed significantly better in terms of cyclic fatigue resistance.

\section{REFERENCES}

1. Ugur Inan, and Cumhur Aydin. Comparison of cyclic fatigue resistance of three different rotary nickel-titanium instruments designed for retreatment. JEndod 2012;38: 108-111

2. Alanna Junaid, Laila Gonzales Freire, Carlos Eduardo da Silveira Bueno, Isabel Mello, and Rodrigo Sanches Cunha. Influence of Single-file Endodontics on Apical Transportation in Curved Root Canals: An Ex Vivo Micro-Computed Tomographic Study. J Endod 2014;40:717-720

3. Brandon Yamamura, Timothy C. Cox, Belal Heddaya, Natasha M. Flake, James D. Johnson and Avina Paranjpe. Comparing Canal Transportation and Centering Ability of EndoSequence and Vortex Rotary Files by Using Micro-Computed Tomography. J Endod 2012;38:1121-1125

4. Kadir T. Ceyhanli, Necdet Erdilek, Ilkan Tatar, and Bekir Çetintav. Comparative micro-computed tomography evaluation of apical root canal transportation with the use of ProTaper, RaCe and Safesider systems in human teeth. Aust Endod J 2014;40: 12-16

5. Yong Gao, Vincent Shotton, Kevin Wilkinson, Greg Phillips, and William Ben Johnson. Effects of Raw Material and Rotational Speed on the Cyclic Fatigue of ProFile Vortex Rotary Instruments. J Endod 2010; 36:1205-1209

6. Gaurav Garg, Sanjay Miglani, Seema Yadav, Sangeeta Talwar. A Comparative Evaluation of Cyclic Fatigue Resistance of Two Rotary Nickel - Titanium Endodontic Systems - An In Vitro Study. Endodontology 2008;22-26

7. Richard Gergi, Joe Abou Rjeily, Joseph Sader, and Alfred Naaman. Comparison of Canal Transportation and Centering Ability of Twisted Files, Pathfile-ProTaper System, and Stainless Steel Hand K-Files by Using Computed Tomography. J Endod 2010;36:904-907

8. Nilav Bhagabati, Seema Yadav and Sangeeta Talwar. An In Vitro Cyclic Fatigue Analysis of Different Endodontic NickelTitanium Rotary Instruments. J Endod 2012;38:515-518

9. O. A. Peters, A. K. Gluskin, R. A. Weiss and J. T. Han. An in vitro assessment of the physical properties of novel Hyflex nickel-titanium rotary instruments. Int Endod J 2012; 1-8

10. Peters OA. Current challenges and concepts in the preparation of root canal systems: a review. J Endod 2004;30:559-67.

11. Wu MK, Fan B, Wesselink PR. Leakage along apical root fillings in curved root canals. Part I: effects of apical transportation on seal of root. J Endod 2000;26:210-6.
12. Marc Garcia, Fernando Duran-Sindreu, Montse Mercade, Rufino Bueno, and Miguel Roig. A Comparison of Apical Transportation between ProFile and RaCe Rotary Instruments. J Endod 2012; 38:990-992

13. Young JM, Van Vliet KJ. Predicting in vivo failure of pseudoelastic NiTi devices under low cycle, high amplitude fatigue. J Biomed Mater Res B Appl Biomater 2005;72:17-26.

14. Frank C. Setzer and Christian P. Bohme. Influence of Combined Cyclic Fatigue and Torsional Stress on the Fracture Point of Nickel-Titanium Rotary Instruments. J Endod 2013; 39(1):133-137

15. Fife D, Gambarini G, Britto LR. Cyclic fatigue testing of ProTaper NiTi rotary instruments after clinical use. Oral Surg Oral Med Oral Pathol Oral Radiol Endod 2004;97:251-6.

16. Yao JH, Schwartz SA, Beeson TJ. Cyclic fatigue of three types of rotary nickel-titanium files in a dynamic model. J Endod 2006;32:55-7.

17. Lopes HP, Ferreira AA, Elias CN. Influence of rotational speed on the cyclic fatigue of rotary nickel-titanium endodontic instruments. J Endod 2009;35:1013-6.

18. Pruett JP, Clement DJ, Carnes DL Jr. Cyclic fatigue testing of nickel-titanium endodontic instruments. J Endod 1997; 23:77-85

19. N. M. Grande1, G. Plotino, R. Pecci, R. Bedini, V. A. Malagnino \& F. Somma. Cyclic fatigue resistance and threedimensional analysis of instruments from two nickel-titanium rotary systems. Int Endod J 2006;39:755-763

20. L. Testarelli, N.M. Grande, G. Plotino, M. Lendini, G. Pongione, G. De Paolis, F. Rizzo, V. Milana and G. Gambarini. Cyclic Fatigue of Different Nickel-Titanium Rotary Instruments: A Comparative Study The Open Dentistry Journal 2009;3:55-58

21. Kim HC, Yum J, Hur B, Cheung GSP. Cyclic fatigue and fracture characteristics of ground and twisted nickel-titanium rotary files. J Endod 2010;36:147-52.

22. Rodrigues RCV, Lopes HP, Elias C, et al. Influence of different manufacturing methods on the cyclic fatigue of rotary nickeltitanium endodontic instruments. JEndod 2011;37:1553-7.

23. López FU, Travessas JA, Fachin E, Fontanella V, Grecca F. Apical transportation: Two assessment methods. Aust Endod J 2009;35:85-8.

24. Sidney GB, Batista A, Melo LL. The radiographic platform: A newmethod to evaluate root canal preparation in vitro. J Endod 1991;17:570-2.

25. Tasdemir T, Aydemir H, Inan U,Unal O. Canal preparation with Hero 642 rotary Ni-Tiinstruments compared with stainless steel hand $\mathrm{K}$-file assessed using computed tomography. Int Endod J 2005;38:402-8.

26. Hülsmann M, Gressmann G, Schäfers F. A comparative study of root canal preparationusing FlexMaster and HERO 642 rotary Ni-Ti instruments. Int Endod J 2003;36:358-66.

27. Peters OA, Scho" nenberger K, Laib A. Effects of four Ni-Ti preparation techniques on root canal geometry assessed by micro computed tomography. Int Endod J 2001;34:221-30. 
28. Wu MK, Fan B, Wesselink PR. Leakage along apical root fillings in curved root canals. Part I: effects of apical transportation on seal of root fillings. J Endod 2000;26:210-6.

29. Fernando Duran-Sindreu, Marc Garcia, Juan Gonzalo Olivieri, Montse Mercade, Sergio Morello and Miguel Roig. A Comparison of Apical Transportation between FlexMaster and Twisted Files Rotary Instruments. J Endod 2012;38:993-989

30. Laila Gonzales Freire, Giulio Gavini, Fernando BrancoBarletta, Rodrigo Sanches-Cunha and Marcelo dos Santos. Microscopic computerized tomographic evaluation of root canal transportation prepared with twisted or ground nickeltitanium rotary instruments. Oral Surg Oral Med Oral Pathol Oral Radiol Endod 2011;112:e143-e148
31. Mateus Silveira Martins hartmann, Vania regina camargo fontanella, José roberto vanni; Volmir joao fornaril Fernando Branco. CT Evaluation of Apical Canal Transportation Associated with Stainless Steel Hand Files, Oscillatory Technique and ProTaper Rotary System. Braz Dent J 2011; 22(4): 288-93

32. Marc Garcia, Fernando Duran-Sindreu, Montse Mercade, Rufino Bueno, and Miguel Roig. A Comparison of Apical Transportation between ProFile and RaCe Rotary Instruments. J Endod 2012; 38:990-992

33. Ricardo Castello Escriv, Teresa Alegre-Domingo, Vicente Faus-Matoses, Sophie Roman-Richon and Vicente J. FausLlacer. In Vitro Comparison of Cyclic Fatigue Resistance of ProTaper, WaveOne, and Twisted Files. J Endod 2012;38:1521-1524

\section{Source of Support: Nil, Conflict of Interest: None Declared}

